\title{
Effects of meteorological conditions on the risk of ischemic stroke events in patients treated with alteplase \\ -HEWS-tPA-
}

Yoshimasa Sueda, $\mathrm{MD}, \mathrm{PhD}^{1}$; Naohisa Hosomi, $\mathrm{MD}, \mathrm{PhD}^{2}$; Miwako Tsunematsu, $\mathrm{PhD}^{3}$; Kazuhiro Takamatsu, $\mathrm{MD}^{4}$; Eiichi Nomura, $\mathrm{MD}, \mathrm{PhD}^{5}$; Tsuyoshi Torii, $\mathrm{MD}, \mathrm{PhD}^{1}$; Toshiho Ohtsuki, MD, DMSc²; Shiro Aoki, MD, $\mathrm{PhD}^{2}$; Tomoya Mukai, $\mathrm{MD}^{2}$; Tomohisa Nezu, $\mathrm{MD}^{2}$; Masayuki Kakehashi, $\mathrm{PhD}^{3}$; Masayasu Matsumoto, $\mathrm{MD}, \mathrm{PhD}^{2}$; on behalf of the HEWS-tPA collaborators $^{6}$

1) Department of Neurology, National Hospital Organization Kure Medical Center, Kure, Japan

2) Department of Clinical Neuroscience and Therapeutics, Hiroshima University Graduate School of Biomedical and Health Sciences, Hiroshima, Japan

3) Department of Health Informatics, Hiroshima University Graduate School of Biomedical and Health Sciences, Hiroshima, Japan

4) Department of Neurology, Brain Attack Center Ota Memorial Hospital, Fukuyama, Japan

5) Department of Neurology, Suiseikai Kajikawa Hospital, Hiroshima, Japan

6) Hiroshima 'Emergency and Weather' Study group (http://home.hiroshima-u.ac.jp/hews)

Grant support: This study was supported in part by research grants from the Ministry of Health, Labour and Welfare of Japan, the Japan Science and Technology Agency, the Smoking Research Foundation, the Tsuchiya Foundation, and the Japan Heart Foundation.

Address correspondence to: Naohisa Hosomi, MD, PhD, FAHA 
Department of Clinical Neuroscience and Therapeutics, Hiroshima University Graduate School of Biomedical Sciences

1-2-3 Kasumi, Minami-ku, Hiroshima 734-8551, Japan

Fax: +81-82-505-0490. Tel: $+81-82-257-5201$

E-mail: nhosomi@hiroshima-u.ac.jp

Cover title: The effect of weather on ischemic stroke events 


\section{Abstract}

Background: Predicting a day that presents a high risk for the occurrence of ischemic stroke events may enable health professionals to prepare for emergency stroke therapy more properly. We evaluated the association between meteorological conditions and the frequency of ischemic stroke events in Japanese patients. Methods: Ischemic stroke patients $(\mathrm{n}=299)$ were examined who were treated with alteplase at nine stroke hospitals in three restricted area. The daily rates of ischemic stroke events were compared to the daily mean thermo-hydrological index (THI), the atmospheric pressure, and the daily changes of these variables for the six days preceding an ischemic stroke event using Poisson regression analysis. Results: We trisected onset days based on the THI (low-temperature, intermediate-temperature, and high-temperature), atmospheric pressure (low-pressure, intermediate-pressure, and high-pressure), changes in THI for preceding six days from the previous day (cooler, unchanged-temperature, and warmer), and changes in atmospheric pressure (decreased-pressure, unchanged-pressure, and increased-pressure). The frequency of ischemic stroke was significantly higher on low-temperature or high-pressure days (Risk Ratio [RR] 1.398, $P=.022$; RR 1.374, $P=.039$ ), on warmer-temperature days, and when atmospheric pressure varied from the day before $(P$ $<.05)$. There were significantly lower risks for ischemic stroke events on cooler-temperature days, and higher risks were associated with a variation in atmospheric pressure three days before the onset from the four days before $(P<.05)$. Conclusions: There were higher risks for ischemic stroke events associated with low ambient temperature, high atmospheric pressure, increased temperature, and varied atmospheric pressure. Also, atmospheric pressure variation in three days before may associate. Key Words: meteorological conditions, ischemic stroke, stroke, prediction 


\section{Introduction}

Stroke is one of the most important diseases afflicting the public because of its high frequency and lethality. For ischemic stroke, patients are treated with emergency interventions including intravenous tissue-plasminogen activator or mechanical intervention in the early acute phase. Identifying high-risk days for the occurrence of ischemic stroke events may allow the public and emergency staff the opportunity to provide a more effective thrombolytic therapy.

The association between meteorological factors, morbidity, and mortality, especially in cardiovascular or respiratory disease, has been reported by various studies. ${ }^{1,2}$ Diseases that are affected by changes in daily weather conditions, such as cardiovascular and respiratory disease, are called meteorotropic diseases. Several studies have demonstrated a seasonal variation and an influence of meteorological factors on the occurrence of ischemic stroke events. ${ }^{3,4}$ Some studies have shown that low ambient temperature is associated with an increase in ischemic stroke occurrence ${ }^{5,6}$; while others have shown that high ambient temperatures are associated with an increase in the incidence of ischemic stroke. ${ }^{7}$ Therefore, there is still considerable controversy as to whether there are any influences of meteorological factors on stroke occurrence.

If we can elucidate the relationship between the occurrence of ischemic stroke events and meteorological conditions, including ambient temperature and atmospheric pressure, we may be able to predict high-risk days for the occurrence of ischemic stroke. In the present study, we evaluated the association between meteorological conditions and the frequency of ischemic stroke events in Japanese patients treated with alteplase at nine hospitals in the prefecture of Hiroshima, Japan. 


\section{Methods}

\section{Patients}

We enrolled consecutive ischemic stroke patients treated with alteplase at nine emergency hospitals in the Hiroshima prefecture, which includes the cities of Hiroshima (four hospitals), Kure (three hospitals), and Fukuyama (two hospitals), from September 2006 to August 2009. These three cities have local meteorological observatories that were used as the source of meteorological data. The onset date and subtype of ischemic stroke were recorded for each patient. The subtypes of ischemic stroke were classified according to the National Institute of Neurologic Disorders and Stroke Classification as lacunar infarction, atherothrombotic brain infarction, cardioembolic stroke, and other. ${ }^{8}$ Ethics committee approval is not required for studies using anonymous data.

\section{Study Area}

Japan is located in a temperate climate zone and has four distinct seasons: spring, summer, autumn, and winter. The Hiroshima prefecture is located in the western part of Japan (North latitude 34-35 degrees and East longitude 132-133 degrees). The three cities included in this study are located in the coastal area of Seto Inland Sea (Fig 1).

\section{Meteorological Data}

The meteorological data analyzed in this study included daily mean ambient temperature $\left(\mathrm{Ta},{ }^{\circ} \mathrm{C}\right)$, daily mean atmospheric pressure $(\mathrm{hPa})$, and daily mean relative humidity $(\mathrm{RH}, \%)$ obtained from each local meteorological observatory (Japan Meteorological Agency, Ministry of Land, Infrastructure, Transport and Tourism). The thermo-hydrological index (THI, $\left.{ }^{\circ} \mathrm{C}\right)$ was calculated with the formula THI $=\mathrm{Ta}-.55 *(1-.01 * \mathrm{RH}) *(\mathrm{Ta}-14.5)$, as reported previously. ${ }^{9}$ This index has been established as an appropriate measure for the evaluation of the effect of air 
temperature on health outcomes because it takes into account mean air temperature after controlling for the effect of relative humidity. The distance from each hospital to the local meteorological observatory ranged from $.2 \mathrm{~km}$ to $12.8 \mathrm{~km}$ (average distance $=5.6 \mathrm{~km}$ ). All the meteorological data were obtained from the website of each local meteorological observatory. The daily rates of ischemic stroke events for each city were compared to the daily mean THI, daily mean atmospheric pressure, and their changes for the preceding six days before the onset of an ischemic stroke event from the previous day.

\section{Statistical Analysis}

The data are expressed as the means \pm standard deviations $(\mathrm{SD})$ or the medians (minimum and maximum) for the continuous variables and as frequencies and percentages for the discrete variables. Daily event rates (95\% confidential interval [CI]) of each month and of each tertile subgroup were calculated using the value of standard error. The relative risk (risk ratio $[R R]$ ) and the $95 \% \mathrm{CI}$ were estimated, controlling for the area of the hospitals, using a Poisson regression model in PASW statistics for Windows, version 18 (IBM Japan Inc., Tokyo, Japan). A $P<.05$ was considered statistically significant.

\section{Results}

During the 3-year observation period of this study, 299 patients (186 men and 113 women) with ischemic strokes were treated with alteplase within 3 hours of the onset of the ischemic stroke. The mean age of the study participants was 73.8 years (median 75 years; range $28-97$ years). Most of the patients were classified as having a cardioembolic stroke (202 patients,

$67.6 \%)$. Seventy patients $(23.4 \%)$ were classified as having an atherothrombotic brain infarction, 15 patients $(5.0 \%)$ were classified as having a lacunar infarction, and 12 patients had ischemic strokes classified as other. 
The annual mean THI from the three cities was $16.2 \pm 6.6^{\circ} \mathrm{C}$. The monthly mean THI ranged from $7.3 \pm 1.7{ }^{\circ} \mathrm{C}$ in January to $25.6 \pm 1.4{ }^{\circ} \mathrm{C}$ in August (Fig 2). The annual mean atmospheric pressure in the study area was $1012.7 \pm 7.3 \mathrm{hPa}$. The monthly mean atmospheric pressure ranged from $1004.9 \pm 2.0 \mathrm{hPa}$ in July to $1019.8 \pm 5.2 \mathrm{hPa}$ in January. The annual mean THI in Fukuyama city $\left(15.8 \pm 6.9^{\circ} \mathrm{C}\right)$ was significantly lower than in Kure city $\left(16.5 \pm 6.3{ }^{\circ} \mathrm{C}\right.$, $P=.039)$. The annual mean atmospheric pressure in Hiroshima city $(1008.8 \pm 6.7 \mathrm{hPa})$ was significantly lower than in Kure city and Fukuyama city $(1014.5 \pm 6.7 \mathrm{hPa}$ and $1014.8 \pm 6.8 \mathrm{hPa}$, $P<.001 ;$ respectively).

The daily event rates of ischemic stroke in each month are shown in Fig 2. The daily event rates in April, December, February, and January were significantly higher than in August ( $P$ $<.05$, respectively).

\section{Association between the frequency of the ischemic stroke events, temperature, and}

\section{atmospheric pressure}

We trisected the days analyzed based on the daily mean THI (low-temperature, $<11.9^{\circ} \mathrm{C}$; intermediate-temperature, $11.9-20.0^{\circ} \mathrm{C}$; and high-temperature, $\geq 20.1^{\circ} \mathrm{C}$ ) and the daily mean atmospheric pressure (low-pressure, $<1009.3 \mathrm{hPa}$; intermediate-pressure, 1009.3-1016.3 hPa; and high-pressure, $\geq 1016.4 \mathrm{hPa}$ ). The frequency of ischemic stroke events was significantly higher on low- and intermediate-temperature days than on high-temperature days (.102/day, 95\% CI .083-.121, RR 1.398, 95\% CI 1.049-1.863, $P=.022 ; .098 /$ day, 95\% CI .079-.116, RR 1.339, 95\% CI 1.002-1.789, $P=.048$; and .073/day, 95\% CI .057-.089, reference for RR; respectively; Fig 3a). When examining the effects of atmospheric pressure, we found that the frequency of ischemic stroke events was higher on high-pressure days than on low-pressure days (.099/day, 95\% CI .080-.118, RR 1.374, 95\% CI 1.017-1.858, $P=.039$; and .078/day, 95\% CI .061-.095, reference for RR; respectively; Fig 3b). 


\section{Association between the frequency of ischemic stroke events and daily change in mean}

\section{temperature and atmospheric pressure}

We trisected the days analyzed based on changes in the mean THI from the previous day for the six days preceding the onset of an ischemic stroke event (cooler, $<-.40{ }^{\circ} \mathrm{C}$; unchanged-temperature, $-.40-.52{ }^{\circ} \mathrm{C}$; warmer, $\geq .53{ }^{\circ} \mathrm{C}$ ) and the change in the mean atmospheric pressure from the previous day for the six days preceding the event (decreased, $<$ $-1.29 \mathrm{hPa}$; unchanged-pressure, $-1.29-1.60 \mathrm{hPa}$; increased, $\geq 1.61 \mathrm{hPa}$ ). The frequency of ischemic stroke events was significantly higher on warmer days than on unchanged-temperature days with the changes in the event days from one day before (.115/day, 95\% CI .095-.135, RR 1.446, 95\% CI 1.099-1.902, $P=.008$; and .078/day, 95\% CI .062-.095, reference for RR; respectively; Fig 4a). The frequency of ischemic stroke events was significantly higher on decreased-pressure and increased-pressure days than on unchanged-pressure days with the changes in the event days from one day before (.104/day, 95\% CI .085-.124, RR 1.497, 95\% CI 1.120-2.001, $P=.006 ; .098 /$ day, 95\% CI .079-.118, RR $1.411,95 \%$ CI $1.052-1.891, P=.021$; and $.070 /$ day, 95\% CI .054-.085, reference for RR; respectively; Fig 5a).

The frequency of ischemic stroke events was significantly lower when there was a decrease in temperature compared with unchanged-temperature days in the three days preceding the event from the previous day $(.073 /$ day, 95\% CI .056-.090, RR .706, 95\%CI .530-.941, $P$ $=.017$; and .102/day, 95\% CI .084-.121, reference for RR; respectively; Fig 4d). The frequency of ischemic stroke events was significantly higher when atmospheric pressure varied (decreased or increased) in the three days prior to the onset of an ischemic event from the previous day (.102/day, 95\% CI .082-.121, RR 1.452, 95\% CI 1.084-1.944, $P=.012 ; .101 /$ day, 95\% CI .083-.120, RR 1.451, 95\% CI 1.084-1.942, $P=.012$; and .070/day, 95\% CI .054-.086, 
reference for RR; respectively; Fig 5d).

\section{Discussion}

In this study, we have evaluated the relationship between meteorological conditions and the risk of ischemic stroke events in patients treated with alteplase in Hiroshima prefecture, Japan. The present study showed that there was a significantly higher risk for the occurrence of ischemic stroke events on low-temperature or high-pressure days. In addition, there was a significantly higher risk for the occurrence of ischemic stroke events on warmer temperature days and on days when there was a variation in atmospheric pressure from the day before. Furthermore, there was a significantly lower risk for ischemic stroke events on cooler-temperature days, and a higher risk for ischemic stroke events on days when there was a variation in atmospheric pressure in the three days before from the previous day.

The frequency of ischemic stroke events was significantly higher in low-temperature days than on high-temperature days. Particularly, the frequency of cardioembolic stroke events showed similar trend, while the frequency of non-cardioembolic stroke was high only on low-temperature days (not statistically significant, data were not shown). Our findings might be affected by the frequency of cardioembolic stroke events account for $67.6 \%$ of evaluated subjects. Similar to our findings, the association between low ambient temperature and the occurrence of ischemic stroke has been observed in several countries. ${ }^{5,6}$ Only study in Israel have shown that high ambient temperatures are associated with an increase in the incidence of ischemic stroke. ${ }^{7}$ A possible reason for this discrepancy might be differences in the climate, population characteristics, and proportion of stroke subtypes of the studied areas.

Several factors may influence the ischemic stroke events, which may help to explain the association between low ambient temperature and an increase in the occurrence of ischemic stroke events. In colder weather, the levels of blood pressure, serum cholesterol, C-reactive 
protein, plasma fibrinogen, factor VII clotting activity plasma values, red blood cells, and platelet counts have been shown to be higher. ${ }^{10-12}$ These physiological conditions, which are associated with cold weather, are known to increase the risk of ischemic stroke.

The frequency of ischemic stroke events was $45 \%$ higher on days when the THI increased $\geq .53{ }^{\circ} \mathrm{C}$ from the day before compared to days with unchanged THI. Similar to our findings, a study in Scotland showed that the risk of an ischemic stroke increased by $2.1 \%$ with each $1{ }^{\circ} \mathrm{C}$ increase in mean ambient temperature from the previous day. ${ }^{13}$ However, a study in Portugal reported that the incidence of ischemic stroke events increased by $3.9 \%$ for each $1{ }^{\circ} \mathrm{C}$ decrease in minimum temperature from a day before. ${ }^{14}$ Furthermore, a study in Korea demonstrated an association between exposure to decreasing temperatures and the occurrence of ischemic stroke peaking at approximately $24-54$ hours after the decrease in ambient temperature. ${ }^{15}$ Our findings showed a $20 \%$ increase in the risk of ischemic stroke events when THI decreased $<$ $-.40{ }^{\circ} \mathrm{C}$ in the two days prior to the onset of an ischemic event (not significant) and a $30 \%$ reduction in the risk of ischemic stroke events when the THI decreased three days before. These results suggested that there might be a delayed effect of decreased ambient temperature on ischemic stroke events. It was reported that the blood viscosity was increased in six hours after the cold exposure as well as in one hour, and did not reach its peak even in six hours later ${ }^{11}$. The reason for time delay in the present study might be the time it takes for the change in blood viscosity or coagulation to occur on a cold day.

In our study, the frequency of ischemic stroke events was 35\% higher on high-pressure days. However, a study in Russia showed that low mean atmospheric pressure increased the risk of ischemic stroke events. ${ }^{5}$ The frequency of ischemic stroke events was significantly higher when there was a variation in atmospheric pressure from the day before, and when there was a change three days before. A study in Italy showed that the occurrence of non-lacunar stroke was associated with a decrease in atmospheric pressure from a day before. ${ }^{16}$ It is still unclear 
whether there is any influence of atmospheric pressure on ischemic stroke events. Further detailed studies may clarify the association between atmospheric pressure and ischemic stroke events.

There are several limitations that should be acknowledged in this study. The association between weather conditions and the occurrence of ischemic stroke might be different with age, sex, or stroke subtypes. However, the present study did not have enough power to analyze difference in those factors because of the limited number of patients included. For example, the frequency of cardioembolic stroke events, but not non-cardioembolic stroke events, showed similar trend in trisected THI with total ischemic stroke events shown in this study. Another limitation of this study was that the patients included were restricted to those that were treated with alteplase. This restriction allowed us to determine the date of onset accurately, but made the sample size small. Well-conducted studies that include a large number of patients are needed to clarify the association between the weather conditions and those factors.

\section{Conclusion}

There was a significantly high association between ischemic stroke events and low ambient temperature and high atmospheric pressure. In addition, an increase in ambient temperature and a change in atmospheric pressure from one day before increased the likelihood of ischemic stroke event. Changes in meteorological conditions three days before the onset may also influence the likelihood of ischemic stroke events. This study suggests that it may be possible to predict ischemic stroke events based on meteorological conditions. 


\section{Acknowledgements}

We would like to show our appreciation to the participated HEWS-tPA collaborators. 


\section{References}

1. Analitis A, Katsouyanni K, Biggeri A, et al. Effects of cold weather on mortality: results from 15 European cities within the PHEWE project. Am J Epidemiol 2008;168:1397-1408.

2. Lin $\mathrm{H}, \mathrm{Zhang} \mathrm{Y}, \mathrm{Xu} \mathrm{Y}$, et al. Temperature changes between neighboring days and mortality in summer: a distributed lag non-linear time series analysis. PLoS One 2013;8:e66403.

3. Turin TC, Kita Y, Murakami Y, et al. Higher stroke incidence in the spring season regardless of conventional risk factors: Takashima Stroke Registry, Japan, 1988-2001. Stroke 2008;39:745-752.

4. Goggins WB, Woo J, Ho S, et al. Weather, season, and daily stroke admissions in Hong Kong. Int J Biometeorol 2012;56:865-872.

5. Feigin VL, Nikitin YP, Bots ML, et al. A population-based study of the associations of stroke occurrence with weather parameters in Siberia, Russia (1982-92). Eur J Neurol 2000;7:171-178.

6. Hori A, Hashizume M, Tsuda Y, et al. Effects of weather variability and air pollutants on emergency admissions for cardiovascular and cerebrovascular diseases. Int J Environ Health Res 2012;22:416-430.

7. Berginer VM, Goldsmith J, Batz U, et al. Clustering of strokes in association with meteorologic factors in the Negev Desert of Israel: 1981-1983. Stroke 1989;20:65-69.

8. Special report from the National Institute of Neurological Disorders and Stroke. Classification of cerebrovascular diseases III. Stroke 1990;21:637-676.

9. Panagiotakos DB, Chrysohoou C, Pitsavos C, et al. Climatological variations in daily hospital admissions for acute coronary syndromes. Int J Cardiol 2004;94:229-233.

10. Woodhouse PR, Khaw KT, Plummer M, et al. Seasonal variations of plasma fibrinogen and 
factor VII activity in the elderly: winter infections and death from cardiovascular disease.

Lancet 1994;343:435-439.

11. Keatinge WR, Coleshaw SR, Cotter F, et al. Increases in platelet and red cell counts, blood viscosity, and arterial pressure during mild surface cooling: factors in mortality from coronary and cerebral thrombosis in winter. Br Med J (Clin Res Ed) 1984;289:1405-1408.

12. Gordon DJ, Hyde J, Trost DC, et al. Cyclic seasonal variation in plasma lipid and lipoprotein levels: the Lipid Research Clinics Coronary Primary Prevention Trial Placebo Group. J Clin Epidemiol 1988;41:679-689.

13. Dawson J, Weir C, Wright F, et al. Associations between meteorological variables and acute stroke hospital admissions in the west of Scotland. Acta Neurol Scand 2008; 117:85-89.

14. Magalhaes R, Silva MC, Correia M, et al. Are stroke occurrence and outcome related to weather parameters? Results from a population-based study in northern portugal.

Cerebrovasc Dis 2011;32:542-551.

15. Hong YC, Rha JH, Lee JT, et al. Ischemic stroke associated with decrease in temperature. Epidemiology 2003;14:473-478.

16. Jimenez-Conde J, Ois A, Gomis M, et al. Weather as a trigger of stroke. Daily meteorological factors and incidence of stroke subtypes. Cerebrovasc Dis $2008 ; 26: 348-354$. 


\section{Figure Legends}

Figure 1. Geographical distribution of hospitals included in this study.

Figure 2. Daily event rates of ischemic stroke by month, monthly variation in mean thermo-hydrological index $\left(\mathrm{THI},{ }^{\circ} \mathrm{C}\right)$, and mean atmospheric pressure $(\mathrm{Pa}, \mathrm{hPa})$.

Figure 3. Event rates of ischemic stroke were trisected based on thermo-hydrological index (a) or the atmospheric pressure (b) on the day of ischemic stroke onset. The graph shows the mean THI index $(T)$ and the mean atmospheric pressure $(P) . * P<.050$ vs high temperature. $\uparrow P<.050$ vs low pressure.

Figure 4. Event rates of ischemic stroke were trisected based on the changes in the mean THI of the preceding six days before the onset of the ischemic stroke event from the previous day. 1 st (cooler), $<-.40^{\circ} \mathrm{C} ; 2 \mathrm{nd}$ (unchanged-temperature), $-.40-.52{ }^{\circ} \mathrm{C} ; 3 \mathrm{rd}$ (warmer), $\geq .53{ }^{\circ} \mathrm{C}$. $* P<.050$ vs 2 nd (unchanged-temperature).

Figure 5. Event rates of ischemic stroke were trisected based on the daily changes of mean atmospheric pressure of the preceding six days before the onset of an ischemic event from the previous day. 1st (decreased), <-1.29 hPa; 2nd (unchanged-pressure), -1.29-1.60 hPa; 3rd (increased), $\geq 1.61 \mathrm{hPa} . * P<.050$ vs. 2nd (unchanged-pressure). 


\section{Appendix}

\section{Participating HEWS-tPA Institutions}

\section{Hiroshima city}

Hiroshima City Asa Hospital (Hiroshi Yamashita), Hiroshima City Hiroshima Citizens Hospital (Hiromasa Toji, Tatsuo Kohriyama), Suiseikai Kajikawa Hospital (Eiichi Nomura), and Hiroshima University Hospital (Naohisa Hosomi, Toshiho Ohtsuki, Shiro Aoki, Tomohisa Nezu, Tomoya Mukai, Masayasu Matsumoto).

\section{Kure city}

Chugoku Rousai Hospital (Masatoshi Kitazono, Kanji Yamane), Kure Kyosai Hospital (Tomohide Maeshiro), and National Hospital Organization Kure Medical Center (Yoshimasa Sueda, Tsuyoshi Torii, Atsuo Yamada).

\section{Fukuyama city}

Brain Attack Center Ota Memorial Hospital (Kazuhiro Takamatsu, Shinzo Ota) and Teraoka Memorial Hospital (Atsumi Takenobu). 
Fig 1

- Hiroshima Prefecture

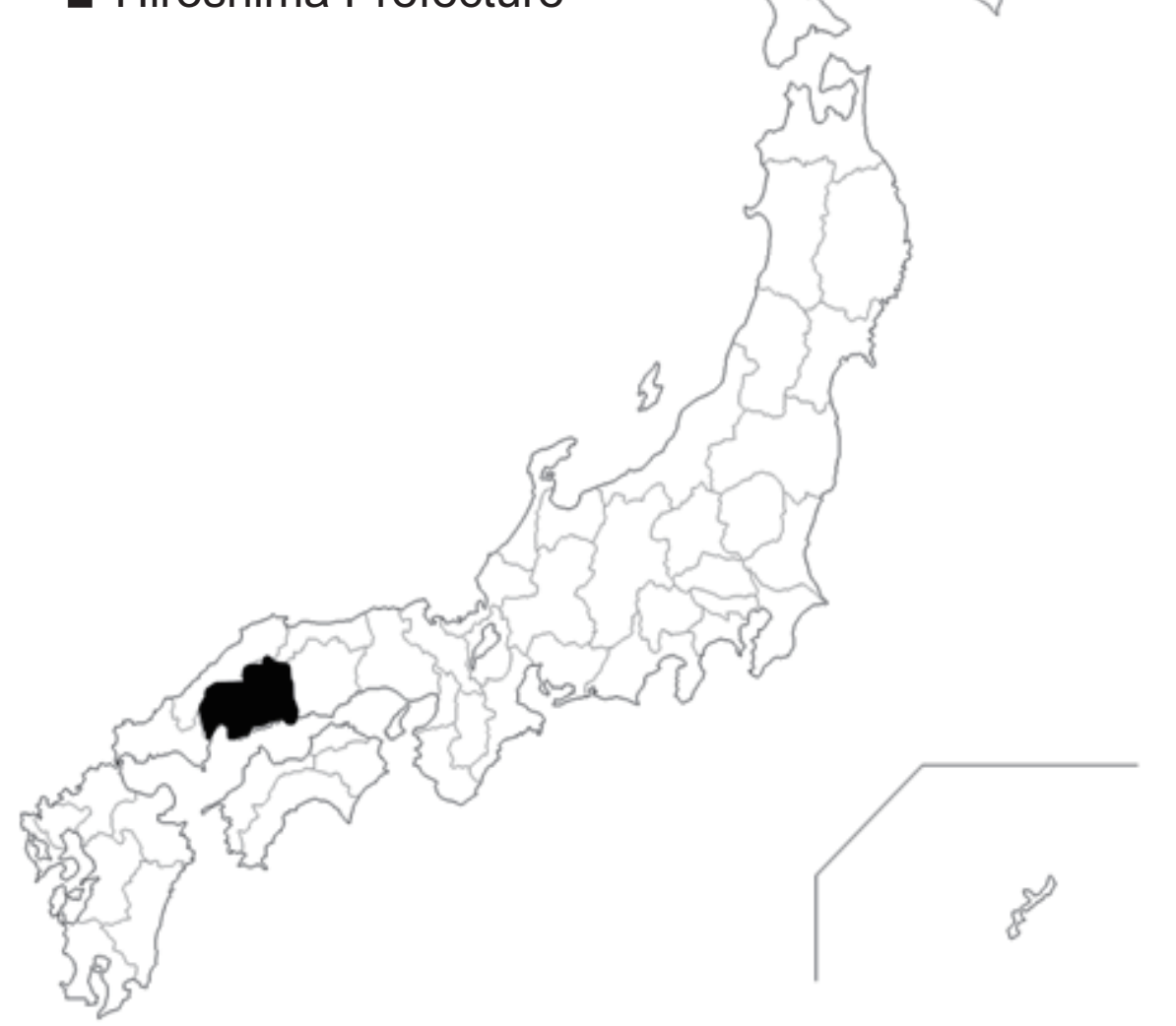

- Participating hospitals

$\square$ Hiroshima Local Meteorological Observatory 
A. Thermohydrological-index

$0.15-$
$0.10-$
$0.05-$
$0-$

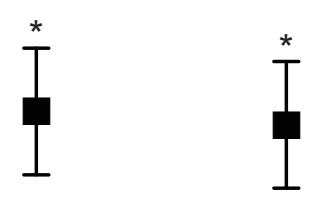

B. Atmospheric pressure

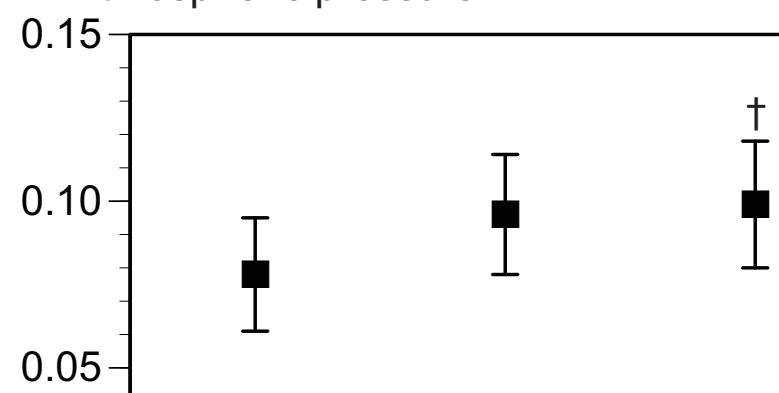

$I$

0

$$
\mathrm{T}<11.9 \quad 11.9 \leq \mathrm{T}<20.1 \quad 20.1 \leq \mathrm{T}
$$

$P<1009.3$ 1009.3 $\leq P<1016.4$ 1016.4 $\leq P$

$n=1102$

$n=1102$

$n=1084$ 


\section{Fig 4}

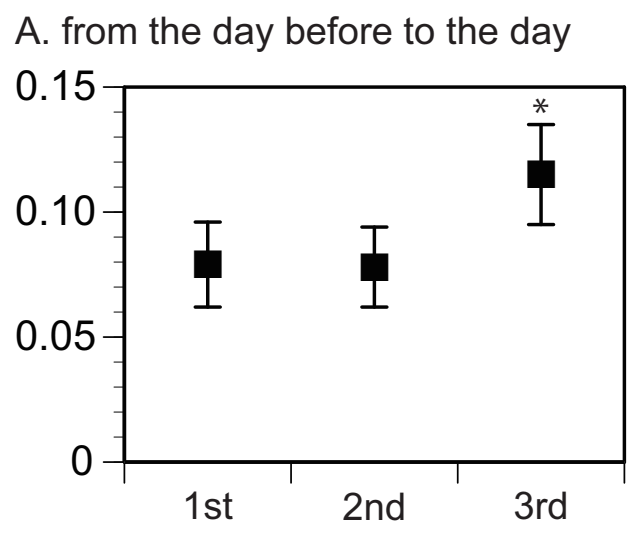
B. from 2 days before to the day before
C. from 3 days before to 2 days before
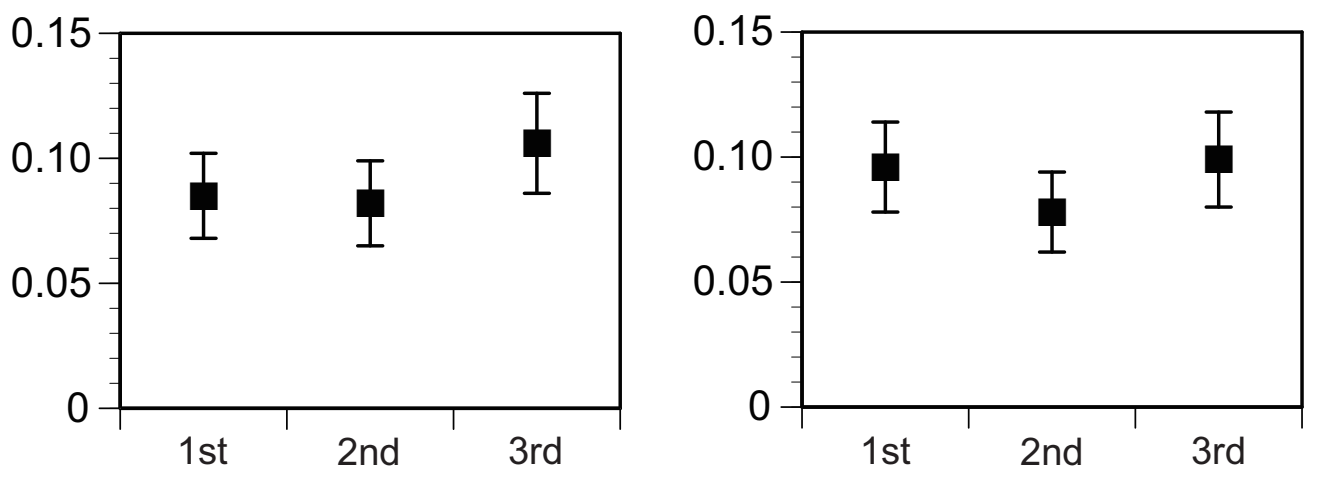

$$
\mathrm{n}=1095 \mathrm{n}=1096 \mathrm{n}=1096
$$

$$
\mathrm{n}=1094 \mathrm{n}=1096 \mathrm{n}=1096
$$$$
\mathrm{n}=1093 \mathrm{n}=1096 \mathrm{n}=1096
$$
D. from 4 days before to 3 days before

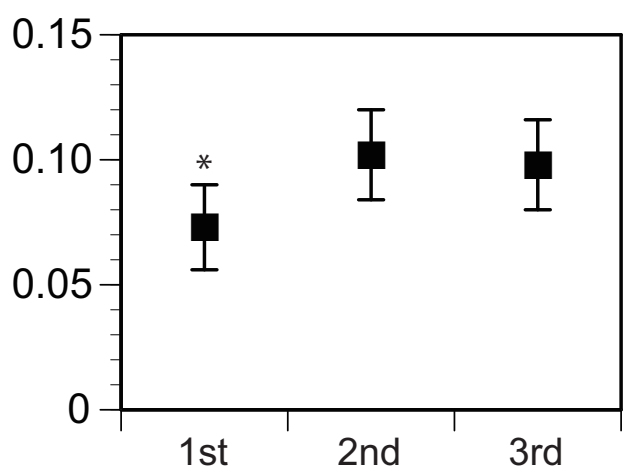
E. from 5 days before to 4 days before

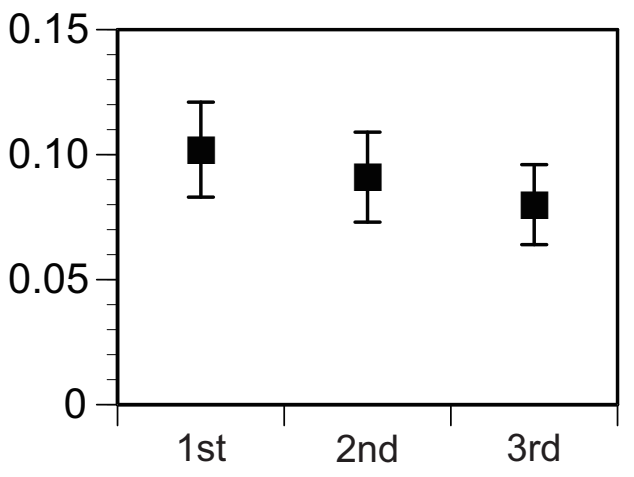
F. from 6 days before to 5 days before

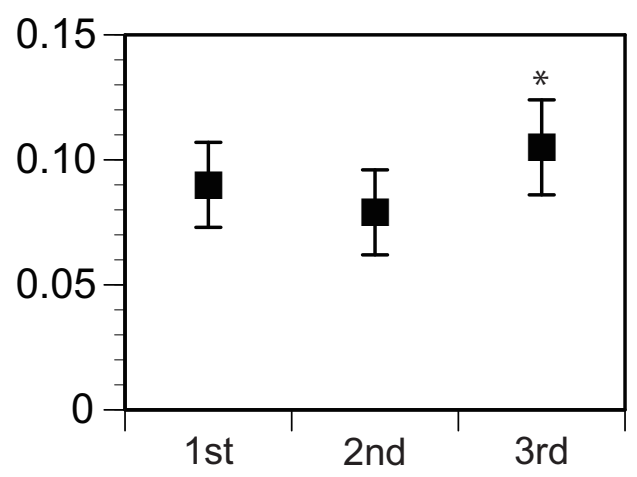

$$
n=1093 \quad n=1095 \quad n=1096
$$

$$
n=1093 \quad n=1095 \quad n=1095
$$


Fig 5
A. from the day before to the day
B. from 2 days before to the day before
C. from 3 days before to 2 days before
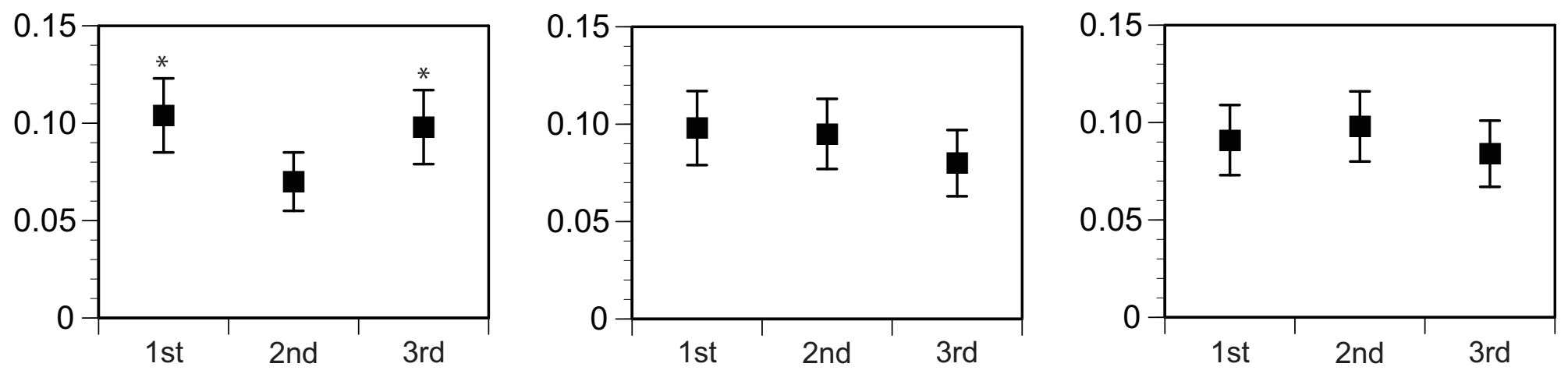

$$
\mathrm{n}=1092 \mathrm{n}=1088 \mathrm{n}=1107
$$

$$
\mathrm{n}=1092 \mathrm{n}=1087 \mathrm{n}=1107
$$$$
\mathrm{n}=1092 \mathrm{n}=1087 \mathrm{n}=1106
$$
D. from 4 days before to 3 days before

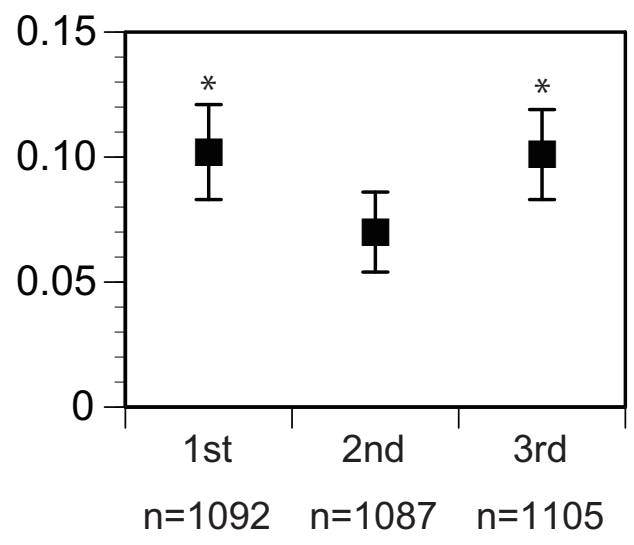
E. from 5 days before to 4 days before

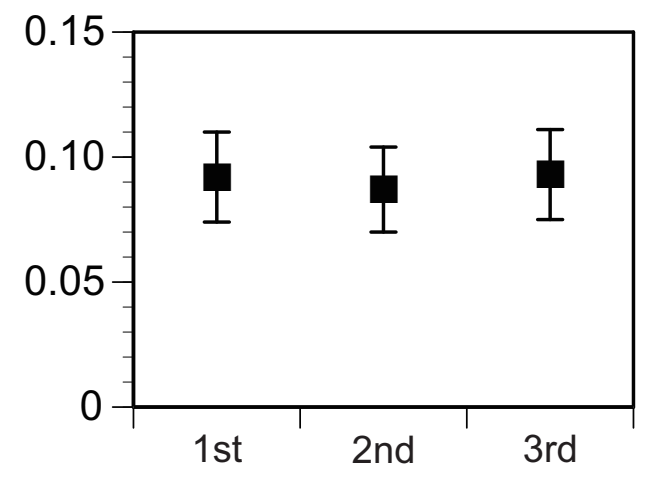
F. from 6 days before to 5 days before

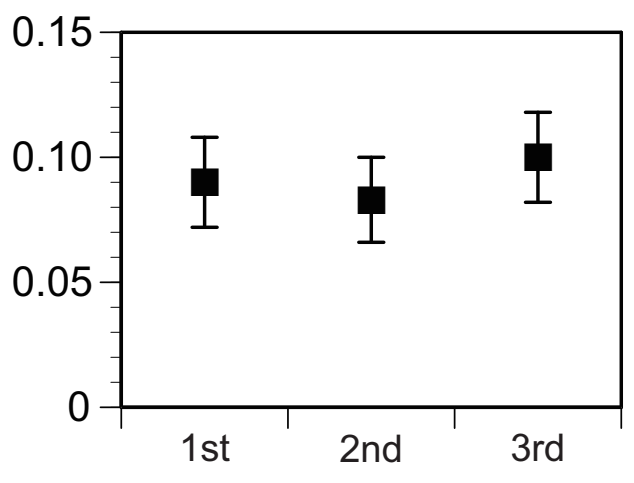

$$
n=1092 \quad n=1086 \quad n=1105
$$

